\title{
Synthesis of Poly(fluorene-alt-thieno[3,4-b]thiophene) for Photovoltaic Devices
}

\author{
Mi-Lim Hwang, Myung-Jin Beak, Wooree Jang, Soo-Hyoung Lee, and Youn-Sik Lee* \\ Division of Chemical Engineering, Nanomaterials Processing Research Center, Chonbuk National University, \\ Chonju, Chonbuk 561-756, Korea.*E-mail: yosklear@jbnu.ac.kr \\ Received May 10, 2011, Accepted July 27, 2011
}

Key Words : Conjugated polymer, Fluorene, Thieno[3,4-b]thiophene, Polymer solar cell

Polymer-based bulk heterojunction solar cells have been fabricated using blended films composed of an electrondonating conjugated polymer and an electron-accepting material such as a fullerene derivative; they are promising low-cost, flexible renewable energy sources. ${ }^{1-4}$ A solar cell's power conversion efficiency (PCE) is the product of the short-circuit current density $\left(J_{\mathrm{sc}}\right)$, open-circuit voltage $\left(V_{\mathrm{oc}}\right)$, and fill factor (FF) divided by the incident light power density. The $V_{\text {oc }}$ of polymer solar cells is generally proportional to the energy difference between the highest occupied molecular orbital (HOMO) of the electron donor and the lowest unoccupied molecular orbital (LUMO) of the electron acceptor, suggesting that polymers with deep HOMO levels are advantageous if conditions are otherwise similar.

Photovoltaic cells have had PCEs of $c a .5 \%$ reported when a mixture of poly(3-hexylthiophene) (P3HT) and a fullerene derivative were respectively used as the electron donor and acceptor. ${ }^{5,6}$ Interesting low band gap polymers consisting of alternating ester or ketone-substituted thieno[3,4- $b]$ thiophene and alkoxybenzo[1,2- $b: 4,5-b$ ]dithiophene units have been developed. ${ }^{7,8}$ Among them, a polymer consisting of a fluorinated ketone-substituted thieno[3,4- $b]$ thiophene and alkoxybenzo[1,2- $b: 4,5-b$ ]dithiophene units, whose band gap and HOMO level were $1.77 \mathrm{eV}$ and $-5.22 \mathrm{eV}$, respectively, exhibited a maximum PCE of $7.73 \%{ }^{9}$

We have also synthesized conjugated polymers for photovoltaic applications. ${ }^{10-12}$ Especially, a polymer consisting of alternating carbazole and ester group-substituted thieno[3,4$b$ ]thiophene units (PCTT1) showed a band gap of $2.1 \mathrm{eV}$ and HOMO level of $-5.52 \mathrm{eV}{ }^{12}$ This polymer, blended with $[6,6]$-phenyl- $\mathrm{C}_{71}$-butyric acid methyl ester $\left(\mathrm{PC}_{71} \mathrm{BM}\right)$, when used as the photoactive layer of solar cells, yielded a maximum PCE of $2.53 \%$.

Polyfluorenes have advantages such as thermal and oxidation stabilities. They can also form films easily and have good hole-transporting properties. The band gaps and HOMO levels of fluorene-containing polymers have been reported to be similar to those of carbazole-containing counterpart polymers, though different PCEs were shown by resulting polymer-based solar cells. ${ }^{13,14}$ Thus poly(fluorenealt-thieno[3,4- $b]$ thiophene polymer) (PFTT) was synthesized as a counterpart of PCTT1. This work describes the synthesis and characterization of the polymer along with preliminary tests of resulting polymer-based photovoltaic devices.

\section{Experimental Section}

Synthesis of PFTT. 2,7-Bis(4,4,5,5-tetramethyl-1,3,2dioxaborolan-2-yl)-9,9-dioctylfluorene ${ }^{15}$ and 2.7-dibromo(2-ethylhexyl)thieno-[3,4- $b]$ thiophene-2-carboxylate ${ }^{16}$ were prepared from 2,7-dibromofluorene and thiophene, respectively, by previously reported procedures. A mixture of 2,7bis(4,4,5,5-tetramethyl-1,3,2-dioxaborolan-2-yl)-9,9-dioctylfluorene $(0.513 \mathrm{mmol})$ and 2.7-dibromo-(2-ethylhexyl)thieno-[3,4-b]thiophene-2-carboxylate $(0.513 \mathrm{mmol}), \mathrm{Pd}_{2}(\mathrm{dba})_{3}$ (30 mg, $5 \mathrm{~mol} \%$ ), tricyclohexyl phosphine (15 mg, 10 mol \%), $20 \mathrm{wt} \%$ tetraethylammonium hydroxide $(2 \mathrm{~mL})$, and chlorobenzene $(7 \mathrm{~mL})$ was refluxed for $48 \mathrm{~h}$ under argon. The reaction mixture was then added dropwise to cold methanol. The resulting precipitate was collected by filtration and washed with acetone in a Soxhlet apparatus for 12 h. After drying under reduced pressure, PFTT was obtained as a red solid.

Measurements. NMR spectra were recorded using a JEOL FT-NMR (400 MHz) spectrometer. The number- and weight-average molecular weights of PFTT were estimated by gel permeation chromatograpy (GPC) using polystyrene standards. UV-visible and photoluminescence emission spectra were obtained on a V-670 (JASCO) spectrophotometer. Thermogravimetric analysis (TGA) of PFTT was performed on a TA instrument Q-50 at $10^{\circ} \mathrm{C} / \mathrm{min}$ under nitrogen. Cyclic voltammetry (CV) was performed on a VersaSTAT3 (METEK) in a solution of tetrabutylammonium hexafluorophosphate $\left(n-\mathrm{Bu}_{4} \mathrm{NPF}_{6}\right)(0.10 \mathrm{M})$ in acetonitrile under argon, at a scan rate of $50 \mathrm{mV} / \mathrm{s}$ at room temperature. Pt wire and $\mathrm{Ag} / \mathrm{Ag}^{+}$were used as the counter and reference electrodes, respectively. Atomic force microscopy (AFM) was carried out using a MultiMode + BioScope (Digital Instruments) in tapping mode.

Fabrication of Photovoltaic Devices. Photovoltaic devices with an active area of $9 \mathrm{~mm}^{2}$ were fabricated with the configuration: ITO/PEDOT:PSS/PFTT:PC ${ }_{71} \mathrm{BM} / \mathrm{LiF} / \mathrm{Al}$. Patterned ITO glasses were ultrasonically cleaned with acetone and isopropyl alcohol, and then treated with $\mathrm{O}_{2}$-plasma. PEDOT: PSS was spin-coated on to the ITO glass and dried at $90{ }^{\circ} \mathrm{C}$ for $20 \mathrm{~min}$ under nitrogen. $\mathrm{LiF}(1.0 \mathrm{~nm})$ and $\mathrm{Al}(150 \mathrm{~nm})$ layers were deposited by thermal evaporation under vacuum $\left(1 \times 10^{-6}\right.$ torr $)$. The $\mathrm{I}-\mathrm{V}$ characteristics of the photovoltaic devices in the dark and under white light illumination were measured. An AM 1.5G solar simulator (Newport) was used 


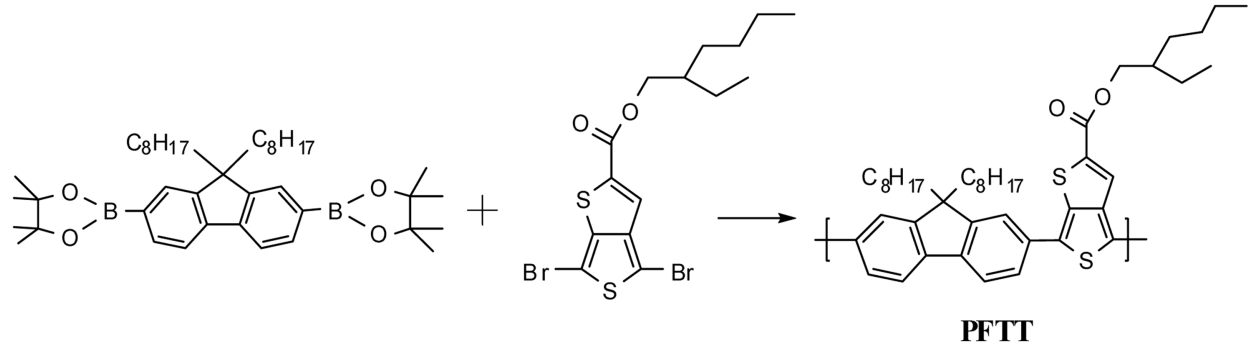

Scheme 1. Synthesis of PFTT.

for illumination at $100 \mathrm{~mW} / \mathrm{cm}^{2}$.

\section{Results and Discussion}

Scheme 1 outlines the synthesis of PFTT. The fluorene and thieno $[3,4-b]$ thiophene derivatives were prepared by reported multi-step procedures. ${ }^{15,16}$ They were combined via Suzuki coupling to yield PFTT, which was completely soluble in common organic solvents such as chloroform, dichlorobenzene, dichloromethane, and $o$-dichlorobenzene at room temperature. The number-average molecular weight $\left(\mathrm{M}_{\mathrm{n}}\right)$ of the polymer was estimated by GPC using polystyrene standard to be 11,000 with a polydispersity index of 2.1. This relatively low molecular weight may have resulted from the non-stoichiometric use of the reactants because the thieno[3,4- $b]$ thiophene derivative was not solid (waxy) and the predetermined amount of each reactant was difficult to measure with high accuracy. (The TGA of the polymer showed $c a$. $5 \mathrm{wt} \%$ loss on heating to $300^{\circ} \mathrm{C}$, indicating sufficient thermal stability for use in polymer solar cells. Neither glass transition nor melting was observed during the DSC experiment, suggesting that the polymer was amorphous in the studied temperature range.

UV-visible absorption spectra of the polymer were recorded in chloroform solution and as a spin-coated film (Fig. 1). The maximum absorption wavelength $\left(\lambda_{\max }\right)$ of PFTT in solution was at $500 \mathrm{~nm}$; PFTT as a thin film had the maximum at $512 \mathrm{~nm}$. Such red-shifting of the absorption maximum (here $c a .12 \mathrm{~nm}$ ) is commonly observed for

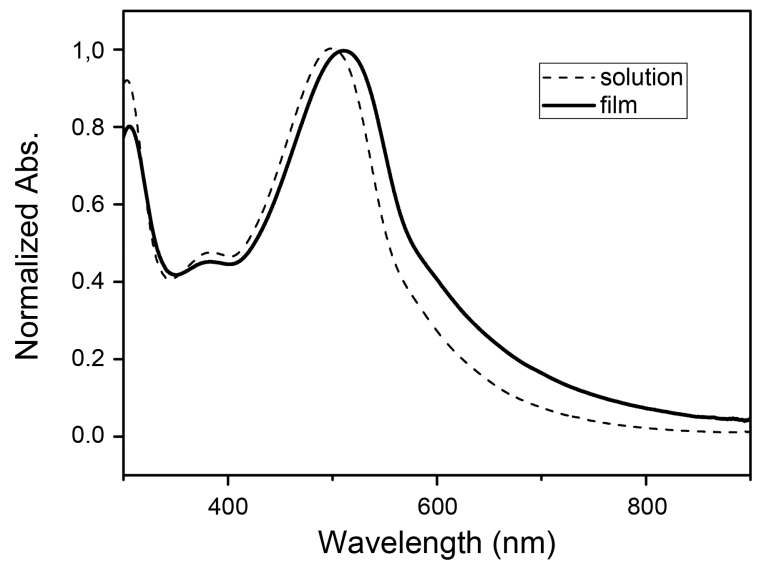

Figure 1. UV-visible absorption spectra of PFTT in solution (chloroform) and thin film. conjugated polymers due to closer interactions when solid. ${ }^{17}$ The optical band-gap ( $\mathrm{E}_{\mathrm{g}}{ }^{\mathrm{opt}}$ ) of PFTT was estimated to be $2.1 \mathrm{eV}$ from the lower energy band edge of the absorption spectrum $\left(\lambda_{\mathrm{ab} \text {, onset }}=590 \mathrm{~nm}\right)$ of the thin film.

The polymer's electrochemical properties were studied by $\mathrm{CV}$ (Fig. 2). The onset oxidation ( $\mathrm{E}^{\mathrm{ox}}{ }_{\text {onset }}$ ) and reduction $\left(\mathrm{E}^{\mathrm{red}}{ }_{\text {onset }}\right)$ potentials were estimated to be $1.08 \mathrm{eV}$ and -0.83 $\mathrm{eV}$, respectively, implying HOMO and LUMO energy levels of $-5.58 \mathrm{eV}$ and $-3.57 \mathrm{eV}$, respectively. Accordingly, the electrochemical band-gap $\left(\mathrm{E}_{\mathrm{g}}^{\mathrm{el}}\right)$ of $2.0 \mathrm{eV}$ was in good agreement with the $\mathrm{E}_{\mathrm{g}}{ }^{\mathrm{opt}}$ value. As expected, the band-gap and HOMO energy level of PFTT were comparable to those of PCTT1 (2.1 eV and -5.52 eV). ${ }^{12}$

Bulk heterojunction solar cells were fabricated using PFTT with a device configuration of ITO/PEDOT:PSS/ PFTT:PC ${ }_{71} \mathrm{BM} / \mathrm{LiF} / \mathrm{Al}$. Their current density-voltage (J-V) curves and external quantum efficiency (EQE) under simulated AM $1.5 \mathrm{G}$ illumination at $100 \mathrm{~mW} / \mathrm{cm}^{2}$ are shown in Figure 3. PCE increased gradually from $0.13 \%$ to $0.69 \%$ with increasing content of $\mathrm{PC}_{71} \mathrm{BM}$ in the PFTT/PC $\mathrm{PC}_{71} \mathrm{BM}$ from 1:1 to $1: 4$. PCE was highest $(0.69 \%)$ in the PFTT-based solar cell when PFTT was mixed with $\mathrm{PC}_{71} \mathrm{BM}$ at a weight ratio of $1: 4\left(J_{\mathrm{sc}}=3.03 \mathrm{~mA} / \mathrm{cm}^{2}, V_{\mathrm{oc}}=0.67 \mathrm{~V}, \mathrm{FF}=0.34\right)$. The spectra show that $\mathrm{EQE}$ increased between $c a .300$ and ca. $500 \mathrm{~nm}$ with increasing $\mathrm{PC}_{71} \mathrm{BM}$ content; less $\mathrm{PC}_{71} \mathrm{BM}-$ dependent absorption variation occurred at longer wavelengths. This indicates that the increase of PCE with increasing content of $\mathrm{PC}_{71} \mathrm{BM}$ was due to short wavelength absorption by $\mathrm{PC}_{71} \mathrm{BM}^{18-20}$

The morphologies of the active layers were studied by

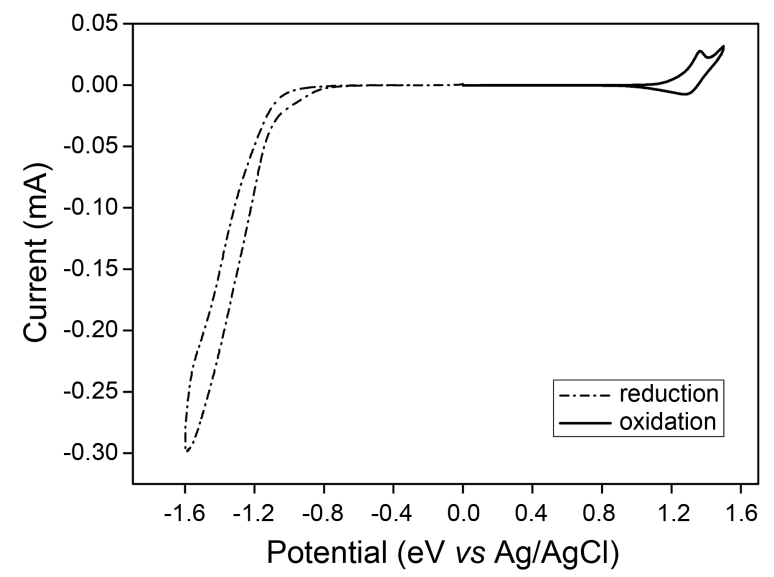

Figure 2. CV curves of PFTT film. 

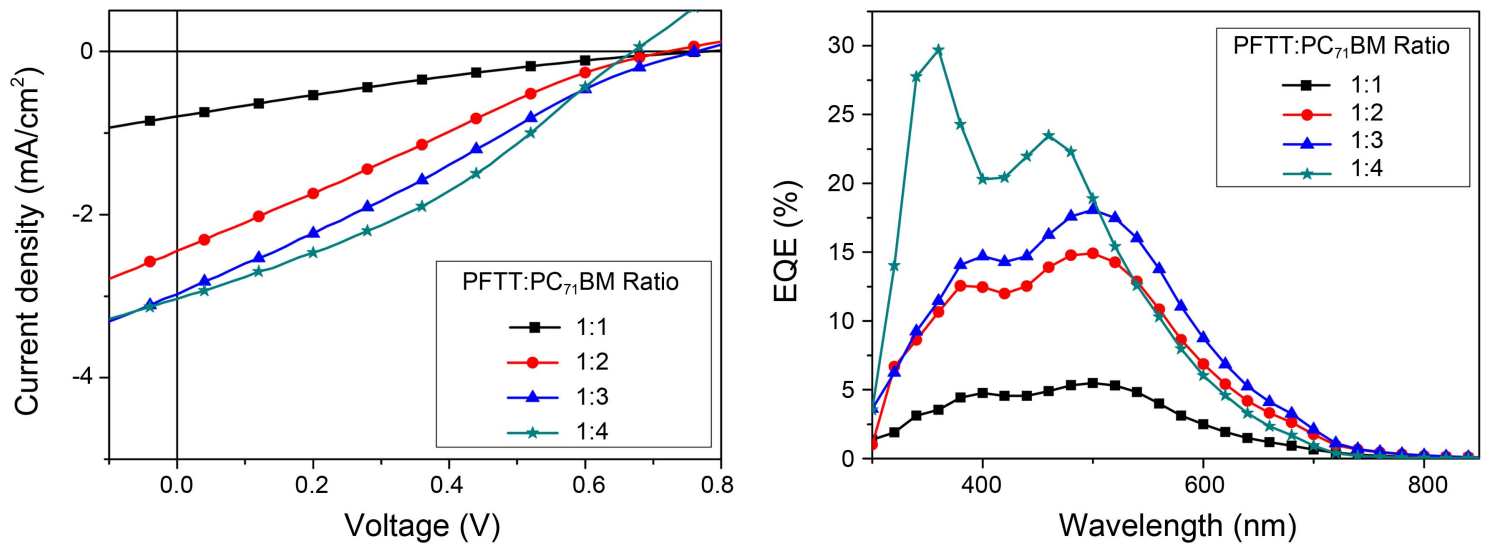

Figure 3. (Left) $\mathrm{J}-\mathrm{V}$ curves and (right) EQE spectra of PFTT-based solar cells under illumination from an AM 1.5G solar simulator $\left(100 \mathrm{~mW} / \mathrm{cm}^{2}\right)$.

Table 1. Characteristics of PFTT-based solar cells ${ }^{a}$

\begin{tabular}{ccccc}
\hline $\begin{array}{c}\text { Ratio } \\
\text { (PFTT:PCBM) }\end{array}$ & $\begin{array}{c}J_{\text {sc }} \\
\left(\mathrm{mA} / \mathrm{cm}^{-2}\right)\end{array}$ & $\begin{array}{c}V_{\text {oc }} \\
(\mathrm{V})\end{array}$ & FF & $\begin{array}{c}\text { PCE } \\
(\%)\end{array}$ \\
\hline $1: 1$ & 0.80 & 0.78 & 0.20 & 0.13 \\
$1: 2$ & 2.44 & 0.72 & 0.23 & 0.41 \\
$1: 3$ & 3.00 & 0.76 & 0.25 & 0.57 \\
$1: 4$ & 3.03 & 0.67 & 0.34 & 0.69 \\
\hline
\end{tabular}

${ }^{a}$ Under similar fabrication conditions, the PCE of P3HT-based solar cells was measured to be $3.5 \%$, with $J_{\mathrm{sc}}=5.79 \mathrm{~mA} / \mathrm{cm}^{2}, V_{\mathrm{oc}}=0.67 \mathrm{~V}$, and $\mathrm{FF}=56$

AFM (Fig. 4). The $\mathrm{PC}_{71} \mathrm{BM}$ aggregates decreased in diameter from $c a$. $400 \mathrm{~nm}$ to $c a .200 \mathrm{~nm}$ with increasing $\mathrm{PC}_{71} \mathrm{BM}$ content. The smaller PCBM aggregates resulted in an increased interfacial area between PFTT and PCBM molecules, increasing PCE. Even the reduced size (ca. 200 $\mathrm{nm}$ ) of the PCBM domains in the PFTT matrix was likely too large to allow high PCE. For comparison, PCTT devices exhibited highest PCE $(2.53 \%)$ when the weight ratio of PCTT1 to $\mathrm{PC}_{71} \mathrm{BM}$ was also $1: 4$, though the $\mathrm{PC}_{71} \mathrm{BM}$ domain size was only 10-15 nm.

Under similar fabrication conditions, the average PCE of P3HT-based solar cells was 3.5\%, despite such devices having had PCEs of $c a .5 \%$ reported under optimized conditions. The HOMO level of PFTT was much deeper than that of P3HT $(-5.58 \mathrm{eV} v s .-4.9 \mathrm{eV})$, resulting in $V_{\mathrm{oc}}$ values of PFTT-based devices being at least similar or greater $(0.67-0.78 \mathrm{~V})$ than those of P3HT-based devices under similar conditions. However, as the PFTT film was amorphous rather than crystalline, its charge mobility may not have been sufficient. The polymer's absorption properties were compared with those of P3HT by analyzing similar concentration solutions in chloroform. The maximum absorption by PFTT was $60 \%$ of that by P3HT; PFTT had a slightly wider absorption range. The absorption range of P3HT solid film was extended by $c a .30 \mathrm{~nm}$, due to its crystallinity $^{21}$ while the absorption spectrum of PFTT solid film was slightly shifted compared with its solution spectrum (by $c a .12 \mathrm{~nm}$ ). These results indicate that the lack of crystallinity (hence low charge mobility) and low light absorption of the active layer resulted in the low PCE of the PFTT-based solar cells.

Despite the band-gap and the HOMO energy level of PFTT being similar to those of PCTT1, resulting polymerbased solar cells performed worse than PCTT1-based solar cells, as the best PCE exhibited by a PCTT1-based solar cell was $2.53 \%\left(\mathrm{PCTT} 1 / \mathrm{PC}_{71} \mathrm{BM}=1: 4, J_{\mathrm{sc}}=4.83 \mathrm{~mA} / \mathrm{cm}^{2}, V_{\mathrm{oc}}\right.$ $=0.98 \mathrm{~V}, \mathrm{FF}=0.5)$ under similar conditions. ${ }^{12}$ The much smaller $J_{\mathrm{sc}}, V_{\mathrm{oc}}$, and FF of the PFTT-based solar cells suggests that the devices may not have been optimized to the extent that the PCTT1-based solar cells were. Furthermore, the absorption coefficient of PFTT at maximum absorption was $c a$. $80 \%$ of that of PCTT1 in solution.

In conclusion, PFTT was successfully synthesized as a complement to PCTT1. Its number-average molecular weight was $11,000 \mathrm{~g} / \mathrm{mol}$, and it was readily soluble in various
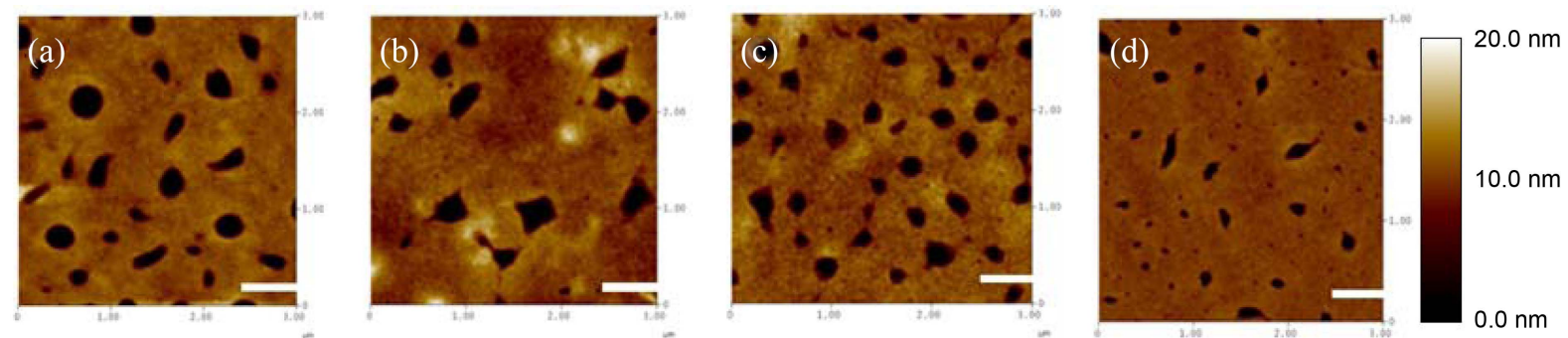

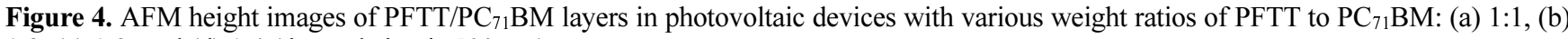
$1: 2$, (c) $1: 3$, and (d) $1: 4$ (the scale bar is $500 \mathrm{~nm}$ ). 
organic solvents. The polymer was amorphous and thermally stable up to $300{ }^{\circ} \mathrm{C}$. Its electrochemical band gap, HOMO and LUMO levels were $2.0,-5.58$, and $-3.57 \mathrm{eV}$, respectively, similar to those of PCTT1. The best PCE achieved by solar cells employing PFTT in a configuration of ITO/ PEDOT:PSS/PFTT:PC ${ }_{71} \mathrm{BM} / \mathrm{LiF} / \mathrm{Al}$ was $0.69 \%$. This $\mathrm{did}$ not compare favorably with PCTT1-based solar cells (max. PCE, $2.53 \%$ ). The lower PCE of the PFTT-based solar cells was primarily attributed to them not being optimized to the same extent as the PCTT1-based devices, the lower light absorption coefficient of PFTT, and large aggregates of PCBM molecules in the polymer matrix.

Acknowledgments. This research was supported by Basic Science Research Program through the National Research Foundation of Korea (NRF) funded by the Ministry of Education, Science and Technology (Grant No. 20100011626).

\section{References}

1. Sariciftci, N. S.; Smilowitz, L.; Heeger, A. J.; Wudl, F. Science 1992, 258, 1474 .

2. Yu, G.; Gao, J.; Hemmelen, J. C.; Wudl, F.; Heeger, A. J. Science 1995, 270, 1789.

3. Halls, J. J.; Walsh, C. A.; Greenham, N. C.; Marseglia, E. A.; Friend, R. H.; Morrati, S. C.; Holmes, A. B. Nature 1995, 376, 498.

4. Kim, J. Y.; Lee, K.; Coates, N. E.; Moses, D.; Nguyen, T.-Q.; Dante, M.; Heeger, A. J. Science 2007, 317, 222.

5. Kim, J. Y.; Kim, S. H.; Lee, H.-H.; Lee, K.; Ma, W.; Gong, X.;
Heeger, A. J. Adv. Mater. 2006, 18, 572.

6. Liang, Y.; Wu, Y.; Feng, D.; Tsai, S.-T.; Son, H.-J.; Li, G.; Yu, L. J. Am. Chem. Soc. 2009, 131, 56.

7. Hou, J., Chen, H.-Y.; Zhang, S.; Chen, R. I.; Yang, Y.; Wu, Y.; Li, G. J. Am. Chem. Soc. 2009, 131, 15586.

8. Liang, Y.; Feng, D.; Wu, Y.; Tsai, S.-T.; Li, G.; Ray, C.; Yu, L. J. Am. Chem. Soc. 2009, 131, 7792.

9. Chen, H.-Y.; Hou, J.; Zhang, S.; Liang, Y.; Yang, G.; Yang, Y.; Yu, L.; Wu, Y.; Li, G. Nature Photon. 2009, 3, 649.

10. Baek, M.-J.; Lee, S.-H.; Zong, K.; Lee, Y.-S. Syn. Met. 2010, 160, 1197.

11. Li, J.-C.; Baek, M.-J.; Kwon, J.-T.; Lee, E.-W.; Lee, S.-H.; Lee, Y.-S. Macromol. Res. 2010, 18, 1237.

12. Baek, M.-J.; Lee, S.-H.; Kim, D. H.; Lee, Y.-S. Macromol. Res. 2011, submitted.

13. Wu, J.-S.; Cheng, Y.-J.; Dubose, M.; Hsieh, C.-H.; Chang, C.-Y.; Hsu, C.-S. Chem. Commun. 2010, 46, 3259.

14. Zhou, E.; Cong, J.; Tajima, K.; Hashimoto, K. Chem. Mater. 2010, $22,4890$.

15. Svensson, M.; Zhang, F.; Veenstra, S. C.; Verhees, W. J. H.; Hummelen, J. C.; Kroon, J. M.; Inganas, O.; Andersson, M. R. Adv. Mater. 2003, 15, 988.

16. Baek, M. J.; Lee, S.-H.; Zong, K. K.; Lee, Y.-S. Syn. Met. 2010 , 160, 1197.

17. Moses, D.-J.; Dogariu, A.; Heeger, A. J. Physical Review B 2000, 61, 9373.

18. Wienk, M. M.; Kroon, J. M.; Verhees, W. J. H.; Knol, J.; Hummelen, J. C.; van Hal, P. A.; Janssen, R. A. J. Angew. Chem. Int. Ed. 2003, 42, 3371.

19. Yao, Y.; Shi, C.; Li, G.; Shrotriya, V.; Pei, Q.; Yang, Y. Appl. Phys. Lett. 2006, 89, 153507.

20. Mühlbacher, D.; Scharber, M.; Morana, M.; Zhu, Z.; Waller, D.; Gaudiana, R.; Brabec, C. Adv. Mater. 2006, 18, 2884.

21. Shrotriya, V. S.; Ouyang, J. Y.; Tseng, R. J.; Li, G.; Yang, Y. Chem. Phys. Lett. 2005, 411, 138. 